\title{
Acceptance of the Howland Award of the American Pediatric Society, 1983
}

\author{
HAROLD E. HARRISON AND HELEN C. HARRISON \\ Department of Pediatrics. The Children's Medical and Surgical Center, The Johns Hopkins Hospital, \\ Baltimore, Maryland, USA
}

HAROLD E. HARRISON

Dr. Nadas, Dr. Finberg, Colleagues, and Friends. It is of course an intense emotional experience to have our names added to the list of those who have been honored by this Society with the Howland Award, particularly because this list includes the names of men and women who have in various ways been our teachers, have inspired our work and contributed to the direction of our careers. As you have often been reminded in the past, one of the unwritten rules for the Howland award is that the recipients be well-ripened and as James L. Gamble wryly remarked, "By the time a man is old enough to be given the Howland award he is too old to have anything to say which would be of interest to this group." I hope that he was talking with tongue in cheek. At any rate we do propose to discuss briefly some historical aspects of our research.

Two major areas of our research have been the homeostasis of potassium and the physiology of vitamin $\mathrm{D}$ and parathyroid hormone with reference to calcium and phosphate homeostasis and bone mineralization.

My research activities began while a second year medical student working in the laboratory of Dr. John P. Peters in the Metabolic Division of the Department of Internal Medicine at Yale. I selected this laboratory for two reasons. First, because I could not understand Peters' lecture on acid-base equilibrium which piqued my pride, and second, because Peters was one of the luminaries at the Yale School of Medicine at that time. However, my specific research was stimulated by the work of James L. Gamble particularly by his paper, "The Metabolism of Fixed Base During Fasting." The term fixed base is probably meaningless to most of you, but, Gamble was measuring the contribution of potassium and of intracellular water to the loss of cation and water from the body during the development of starvation ketoacidosis. Peters had insisted that I develop my own research project and I proposed to do electrolyte balance studies on patients to see if fluctuations of intracellular potassium and water could be measured in certain disease states.

Doing balance studies on an open ward without a clinical research unit and without assistance was an onerous task, but the work gave me an insight into electrolyte physiology and, incidentally, provided my first publication in the Journal of Clinical Investigation.

The major asset of this research project was that I became interested in electrolyte physiology and decided to continue research activity in this field. However, during my clinical work, I became interested in pediatrics because of the influence of a great teacher, Grover Powers. Grover Powers was an extraordinarily able clinician and inspiring teacher but of most importance to me, he was a gentle and humanitarian individual who provided for me the inspiration of the kind of physician which I should like to become. I did not have to change my research goals because in the Department of Pediatrics there was an active investigator in electrolyte physiology, Daniel C. Darrow, with whom I hoped to continue my work. When I told Dr. Peters of my intention to do clinical work in pediatrics, I detected, with some pleasure, that he seemed disappointed but also noted that he regarded my decision to move from internal medicine to pediatrics as a step down on the social scale, a feeling which many internists apparently share.

Darrow was willing to have me work in his laboratory but in his characteristically honest fashion said, "Before you make up your mind, I must tell you that in my opinion the golden age of electrolyte physiology is over." I was startled by this and asked for clarification. He went on to say that there were many interesting problems in electrolyte physiology which still had to be explored but none of these studies would lead to major clinical applications comparable to the two contributions of electrolyte physiology which had already been made, namely the expansion of extracellular fluid volume by administration of sodium chloride solutions and the correction of hydrogen ion excess by administration of sodium bicarbonate or sodium lactate. I was relieved because at that stage in my career, I thought that science was done for the sake of knowledge and that clinical application was not the immediate goal. Darrow had a young associate, Herman Yannet, working with him. We agreed that it would be desirable to continue studies of the homeostasis of intracellular potassium, but felt that balance studies were not sufficiently accurate for this purpose. We decided to attack this problem by the analysis of whole animals determining the concentration of intracellular potassium utilizing the principle that chloride was an entirely extracellular ion so that we could calculate the volume of extracellular fluid of tissue from the chloride content and determine the volume of intracellular fluid and the concentration of intracellular potassium by this indirect method. In order to support the research we applied to the fluid research fund at the Yale Medical School. This was an institutional research grant fund supported by the Rockefeller Foundation. We were pleased that our application was approved and funded for the full amount requested, $\$ 400$. Lest you laugh too vigorously let me point out, that our salaries, such as they were, were paid by the medical school for our role as teachers and supervisors of medical care in the Hospital. Our laboratory was supported by the hospital because it was also a clinical diagnostic laboratory. We had no technicians and no secretaries. The three of us, Darrow, Yannet, and myself, worked side by side in the laboratory, going through the tedious manipulations necessary for analysis of the tissues of whole animals. This was not, however, as boring as it might seem. We worked together and we were inspired by Darrow who was a true scholar. He read widely and thought deeply, and as we went through the familiar procedures, he led us in discussions ranging from religion to history to music to physical chemistry so that we were absorbed in these ideas and did not find the hours of laboratory work at all tedious.

In addition, the results of our analysis quickly proved to be of considerable interest. In the next decade continuing studies were 
able to document that intracellular potassium concentrations could be determined by tissue analysis and that experimental potassium deficiency resulted in a loss of intracellular potassium with replacement by sodium and hydrogen ions. The nature of the physiologic disturbances of potassium deficiency were demonstrated, particularly the effects of potassium deficiency on renal tubule and skeletal muscle function. In studies done both by us and by Darrow, the evidence that serious potassium deficiency resulted from chronic or prolonged diarrheal disease became clear. Darrow was now convinced that it was desirable and even essential to be able to replace such potassium deficiency not only by the oral administration of potassium which was already in use by us and others but also by parenteral administration of potassium. This latter, however, was regarded by most with considerable suspicion because of the dangers of increase of extracellular potassium concentration with consequent cardiac arrest. However, in the summer of 1945 Darrow put his concept into practice. He added potassium to the conventional parenteral fluids used in the treatment of diarrheal dehydration and demonstrated cellular retention of potassium which was sufficiently rapid so that with proper precautions parenteral potassium could be given without raising extracellular potassium to dangerously high concentrations.

Potassium therapy has now become a standard addition to fluid and electrolyte therapy as a supplement to the expansion of extracellular water with sodium chloride and correction of hydrogen ion excess with sodium bicarbonate. The golden age of electrolyte physiology was not over. There never is a golden age because experience has shown that it is difficult to predict what further knowledge will contribute in terms of application to disease processes and therapy thereof.

I left Darrow's laboratory in 1938. This was a difficult decision because the work was so exciting and progressing so well. But, like most young investigators I was anxious to prove that I could do independent research and the opportunity came to head my own electrolyte laboratory at the New York Hospital Cornell Medical College Center. In addition, Helen had finished her work for a Ph.D. in physiological chemistry at Yale that year. We had made the decision to do investigative work together, and this opportunity was made available to us at the New York Hospital. An old friend, Harry Gordon, was in the Department of Pediatrics at Cornell and I was pleased to have the opportunity to join hands with him again in some cooperative ventures.

Helen and I continued to work on potassium and had the opportunity to study potassium deficiency in a number of patients with chronic diarrhea in cooperation with the Department of Medicine utilizing the excellent clinical research unit at the New York Hospital, the Russell Sage Institute. These studies indicated that severe potassium deficiency with marked hypokalemia could occur as a result of losses of potassium in the stool resulting in muscle weakness, hypotension and chronic disability correctable by oral loads of potassium. As stated above, however, in the acute diarrheal states the potassium deficiencies could only be corrected by parenteral potassium until the patient was able to take oral fluids.

In addition to our studies on potassium we began to study the homeostasis of another ion namely phosphate. We attacked this problem by examining the role of renal excretion of phosphate in controlling the concentration of extracellular phosphate. We were able to demonstrate in the dog that extracellular concentration of phosphate was regulated by the maximum rate of tubular reabsorption of phosphate expressed as phosphate reabsorped per volume of glomerular filtrate. The tubular transport of phosphate was inhibited by parathyroid hormone and was reduced in the vitamin D deficient animal explaining the hypophosphatemia in this condition. These studies aroused Dr. Park's interest and as a result he invited us to come to Baltimore to continue studies of Vitamin D in the Department of Pediatrics of the Johns Hopkins University School of Medicine which we did after an interlude of war-related research.
The laboratory studies on the physiology of vitamin $\mathrm{D}$ were Helen's direct responsibility and she will continue in her response with comments on these research efforts and Dr. Park's participation in our work concerning the physiologic mechanism of vitamin $\mathrm{D}$ action.

\section{HELEN C. HARRISON}

Dr. Nadas, members of the American Pediatric Society, and guests. Back in October, when my husband told me that he had received a telephone call from the Council of this Society, indicating that the Howland Award for 1983 was to be given jointly to the two of us, I received the news with complete disbelief, disbelief that $I$ would be included in that group of eminent pediatricians, many of whom I knew well and whom I revered. Tremendous pride now replaces disbelief, and I am truly deeply honored and extremely happy to share this award with my husband.

In 1934, a very wise and wonderful woman, Professor Myra M. Sampson, with whom I was finishing my Master's degree at Smith College, urged me not to take the one available job which she felt compelled to tell me about, but to continue for my Ph.D. at Yale. She repeated many times-I know how difficult the times are, but you will always thank me for this advice. I did not take the job, I did go to Yale, and I have thanked her many times and thank her again now.

At Yale, I was very fortunate, fortunate in many ways. As a graduate student in the Department of Physiological Chemistry at the Medical School, about to select a thesis topic, I heard Dr. C. N. H. Long give a brilliant lecture before the Yale Medical Society on "Diabetes Mellitus, The Role of the Adrenal and Pituitary Glands." I was tremendously impressed by the lecturer and fascinated by the new and exciting area of research into the effects of the endocrine glands on metabolic processes. Dr. Long took over the chairmanship of the Department of Physiological Chemistry the following year, and I was privileged to be his first Ph.D. at Yale and later (after four years at Cornell) to rejoin his Department during World War II (as a postdoctoral fellow) working on the catabolic effects of the adrenal on hemorrhagic shock. For us the Yale connection has always been a very happy and important one.

Soon after our arrival at the Harriet Lane Home, when I was setting up our research laboratory, I met one of the highly regarded practicing pediatricians in Baltimore whom we had known at Yale. After we exchanged greetings, he asked what we would be doing in our research lab, and I casually said, "Working on vitamin D," whereupon he asked, "Don't we know all we need to know about vitamin D?"

Yes, in 1947, we did know essentially all one needed to know about vitamin $D$ to prevent rickets in children and also to treat the common variety of vitamin D-deficiency rickets. But what we did not know was the mechanism of action of this potent compound, nor did we understand adequately the homeostatic mechanisms involved in maintaining calcium and phosphate concentrations in the body, and these were the problems we took as our challenges.

Our early research at Hopkins took several directions; the use of the recently available radioisotope of $\mathrm{Ca},\left[\mathrm{Ca}^{45}\right]$ for intestinal absorption studies, the relation of vitamin $\mathrm{D}$ to the citrate metabolism of the body, the development of animal models for the Fanconi syndrome and for a form of distal renal tubular acidosis leading to renal calcinosis, as well as the interrelationship between vitamin $\mathrm{D}$ and the parathyroid hormone. But it was the adaptation and use of a very simple in vitro technique, the everted gut sac, originally developed by Wilson and Wiseman for the study of the transport of glucose and amino acids that allowed us to investigate the action of vitamin $\mathrm{D}$ at the intestinal cell surface, and the results of these experiments reactivated wide interest in the vitamin D field. With its use, the action of vitamin $\mathrm{D}$ on calcium and phosphate transfer across the intestinal mucosa 
was demonstrated, and the fact that vitamin $\mathrm{D}$ is not active in vitro, but that it must be given to the animal at a definite interval before the gut is removed for in vitro study. These results then led others to a search for the events which occurred during this time interval, giving rise to the work on the calcium binding proteins and the metabolic transformations of vitamin $D$ to its most active hormonal form, 1, 25-dihydroxy vitamin $\mathrm{D}$.

Coincident with the advances in the knowledge of the metabolism and functions of vitamin $\mathrm{D}$ and interrelation with parathyroid hormone was the clinical development of methods for keeping alive patients with progressive renal disease by hemodialysis and kidney transplantation. These patients present serious problems of calcium and phosphate metabolism which can better be understood in the light of the new knowledge of vitamin $D$ metabolism, particularly that the active metabolite, 1, 25-dihydroxy vitamin $\mathrm{D}$, is formed in the kidney. Here again, one may well be impressed by our inability to predict the clinical applications of research done primarily to understand mechanisms.

Throughout all these research efforts, until 1969, our own intellectual curiosity was constantly stimulated and challenged by the person who was responsible for our coming to Hopkins, Dr. Edwards A. Park. How fortunate we were to have arrived at the Harriet Lane at the time of Dr. Park's retirement as Chairman of the Pediatrics Department and be able to share his unabated and boundless enthusiasm for scientific investigation, particularly regarding vitamin $\mathrm{D}$ research and the mysteries of the calcification process. We shared not only his tremendous knowledge in this area, but were also the beneficiaries of his wide erudition: his love and interest in the classics, poetry, history, nature, but most of all we were the beneficiaries of his friendship and affection. Often, after we had been together, whether in the laboratory or at Dr. Park's home, we would receive a note which in effect continued the conversation. We cherish a large collection of such notes and letters. I quote from one written in 1958:

Dear Harold:

Here is what I promised to send. . .

and then Dr. Park quotes from a letter written by Benjamin Franklin to Dr. Joseph Priestley in 1780.

The rapid progress true science now makes, occasions my regretting sometimes that I was born so soon. It is impossible to imagine the heights to which may be carried, in a thousand years, the power of man over matter... .

$\mathrm{O}$, that moral science were in as fair a way to improvement that men would cease to be wolves to one another and that human beings would at length learn what they now improperly call humanity!

and in the postscript of this same letter from Dr. Park

P.S. The birds, the name of which I could not recall, which are localized on an island off the Gaspé peninsula are gannets.

The last letter we received just $5 \mathrm{wk}$ before his death, was a request for a reference to the work going on in the laboratory of Professor Hector DeLuca at the University of Wisconsin on the metabolic transformations of vitamin $\mathrm{D}$ to its hormonal form. In his interest and thinking Dr. Park remained at the forefront of the vitamin $\mathrm{D}$ field to the very end!

We take this occasion to thank the many talented associates who were part of our research. They added immeasurably to the pleasure as well as the progress of our work.

Over the many years of our investigative efforts our rewards have been the joy, excitement, and intellectual gratification which we have experienced in exploring new ideas. Now this Society adds a new dimension in considering our efforts of value in the "promotion of health in childhood." We are deeply grateful for this honor you have bestowed upon us. We thank you most sincerely.

\title{
Identification of the Major 4-Methylumbelliferyl p-Guanidinobenzoate-Hydrolyzing Plasma Protein in Cystic Fibrosis: Implication for Intrauterine and Heterozygote Detection
}

\author{
BRUCE R. BRANCHINI, ${ }^{(39)}$ GINO M. SALITURO, AND BERYL J. ROSENSTEIN \\ Biomedical Research Institute, The University of Wisconsin-Parkside, Kenosha, Wisconsin; Department of \\ Chemistry, The Johns Hopkins University, Baltimore, Maryland; and Department of Pediatrics, The Johns \\ Hopkins University, School of Medicine, Baltimore, Maryland, USA
}

\section{Summary}

Measurement of 4-methylumbelliferyl p-guanidinobenzoate (MUGB)-hydrolyzing activity in the plasma of normal controls, cystic fibrosis (CF) heterozygotes, and CF homozygotes did not support previously reported (35) differences in MUGB-hydrolyzing activity. We identified human plasma albumin as the major source of MUGB-hydrolyzing activity by comparison of our plasma results to those obtained with physiologic concentrations of commercial albumin samples. Substantiating evidence was obtained from gel filtration experiments and correlation of albumin levels in CF plasma with MUGB titers. We found essentially no proteolytic activity towards dinitrophenylprotamine sulfate associated with commercial albumin samples. It appears that the reaction between human albumin and MUGB represents a weak esterase activity, perhaps involving the acylation of a specific site(s) on the protein.

Hypoalbuminemia has been documented (8) in some CF patients. Low albumin concentrations, indicated by MUGB titers $<190$ nmole methylumbelliferone/ml plasma, were found in $42 \%$ 